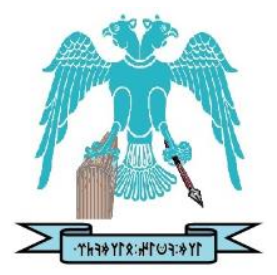

JOURNAL OF ENERGY SYSTEMS

$2019,3(4)$

\title{
A Comparative simulation on the grounding grid system of a wind turbine with FEA software
}

\begin{abstract}
Selami Balci iD
Karamanoğlu Mehmetbey University, Department of Electrical \& Electronic Engineering, Karaman, Turkey, sbalci@kmu.edu.tr

Omerhan Helvaci ${ }^{\text {DD }}$

Karamanoğlu Mehmetbey University, Graduate School of Natural and Applied Sciences, Department of Engineering Sciences, Karaman, Turkey, omerhanhelvaci@gmail.com

\begin{tabular}{rr|l|} 
Submitted: & 31.08 .2019 & \\
Accepted: & 13.12 .2019 & \\
Published: & 31.12 .2019 & $\begin{array}{c}\text { Check for } \\
\text { updates }\end{array}$ \\
\hline
\end{tabular}

Abstract: The mathematical models proposed in the literature are used to determine the grounding resistance value for electrical installations. These models are mathematical expressions that change according to grounding type and the mechanical properties of the grounding system elements. Besides, the inclusion of nonlinear terms is another important issue in the modeling studies. For the modeling of nonlinear systems and the analysis of the faults that may occur, the finite element analysis (FEA) approach provides realistic results. In the present study, the simulation of a grid fault that may occur in the grounding system of a sample wind turbine (WT) is modeled by $2 \mathrm{D}$ electrostatic solver in FEA software. The simulation results prove that the findings are similar to the realistic faults in the grounding system.
\end{abstract}

Keywords: Electrostatic solver, FEA simulation, Grounding faults, Wind turbine

Cite this paper as: Balci, S., Helvaci, O., A Comparative simulation on the grounding grid system of a wind turbine with FEA software. Journal of Energy Systems 2019, 3(4), 148-157, DOI: 10.30521/jes.613724

(c) 2019 Published by peer-reviewed open access scientific journal, JES at DergiPark (https://dergipark.org.tr/en/pub/jes)

\begin{tabular}{r|l} 
Nomenclature & \\
\hline ANSI & American National Standards Institute \\
CEC & Canadian Electrical Codes \\
EN & European Norm \\
FEA & Finite Element Analysis \\
IEC & International Electrotechnical Commission \\
IEEE & Institute of Electrical and Electronics Engineers \\
NEC & National Electrical Codes \\
NESC & National Electrical Safety Code \\
TSE & Turkish Standards Institute \\
VDE & Verband Deutscher Elektroingenieure (Association of German Electrical Engineers) \\
WT & Wind Turbine \\
\hline \hline
\end{tabular}




\section{INTRODUCTION}

The grounding systems are the most important protection measures to protect the life of the living things as well as the installations and other devices. The main function of a grounding system is to be a way to the ground in the case of lightning impulses or leakage currents to the housing. The high value fault currents are distributed in the grounding grid, directly affect the step, and contact (touch) voltages. Thus, in the grounding system, it is necessary to consider certain requirements to avoid the insecure conditions, and hazard level of the voltage in any failure condition [1]. Besides, providing a low grounding resistance is another issue in the electrical protection [1].

In the grounding system, the earth resistance value changes in an unpredictable manner according to the grounding types. However, the geometry of the grounding element and the material type also affect the earth propagation resistance value. This is as important as the grounding systems of buildings as well as in the electricity generation installations of renewable energy plants (i.e. wind and solar plants). This is because the grounding system and the earth spreading resistance against lightning impulses are of great importance in such installations. The grounding system design is of more importance in terms of the effectiveness of protection, considering installation and operating costs in applications such as solar and wind power plants. In this context, for instance, in Ref. [2], the improvement of grounding performance in wind power turbine is explored in wind power plants, and analyzed with computer-aided software. The first and the most important step in the installation of grounding systems is the design of the grounding system. In grounding systems, grounding conductors and grounding rods are used together with grounding grids. As grounding in the installations; rod, sheet and strip grounding are widely used. The designed grounding types are protection grounding, plant grounding and lightning protection grounding.

The contact resistances, earth resistances and contact voltages can be measured experimentally at two different points. The obtained field measurement data are not the same at both points of earth structures. Therefore, it suggests that it is not possible to determine a uniform land characteristic as an optimal model for estimating land grid performance. However, a multi-layer land modeling gives accurate calculation results [3]. In this context, for the first time in Ref. [4], a comprehensive parametric study on the ground grid performance in multi-layered earth structures has been made. For various practical conditions, the grounding grid resistance has been studied. The voltage distributions, earth surface potentials and contact voltages are analyzed comparatively for different region structures in this manner. In addition, the reported results provide a criterion for future studies in this field and indicate practical situations, such as frozen or partially frozen land conditions, which remain a clear question to date, where the multi-layered structure of the earth should be considered in order to ensure a safe grounding system design. The ground grid performance, which can be measured by ground resistance, contact voltages and step voltages, largely depends on the earth structure. Although two-layer land model represents the actual land structure in some cases, it is necessary to use multi-layer land models to accurately model most of the land structures. However, land features, which are close to the surface, can vary considerably even after the grid has been installed. For example, the resistance of the earth surface can increase by up to twice when the land freezes and it becomes sensitive to the moisture content of the earth in the summer time [4]. In this context, a hypothetical model for the analysis of grounding grid systems and unstable earth resistant has been proposed with boundary element method. The analysis stages are explained and the fundamental equations are also given in this context. The analytic and numeric verifications are also performed in the analysis process [5].

IEC 60909 [6] and VDE norms are mainly applied as the international grounding standards. The countries make the necessary arrangements with their own regulations. In this frame, grounding system 
regulations in the TSE Regulation and Electricity Plant are prepared by getting a clue from IEC and EN standards. On the one hand, the requirements for grounding system in North America are obtained from the relevant National and Canadian Electrical Codes (NEC and CEC), the National Electrical Safety Code (NESC) and the standards of various organizations, but initially from IEEE and ANSI. The earth resistance can range from tens of ohms $(\Omega-\mathrm{m})$ in wind farmlands to the tens of thousands $\Omega \mathrm{m}$ in rocky mountain regions. This rarely has the same property on the area of the wind power plant. The choice of grounding system materials and equipment must be performed, because grounding can be scientific and artistic design of the grid structure, thereby, various basic self-design parameter can affect the last installation. These data can then be analyzed with various software and they provide a comprehensive analysis to determine the performances and expectations according to the specific parameters such as grounding system grid geometry [7]. In a different work with the required data from a wind turbine operation in Iran, a different grounding system is proposed and analyzed with the finite element method in MatLab software. The presented grounding system improves a few parameters such as earth resistance, step and contact voltages [1]. Ref. [8] demonstrates the FEA's practical use in the analysis of complicated systems in order to protect one from the electrical power in an industrial system as another application of grounding. The procedure proposed by FEA for the calculation of grounding systems has proven that it is accurate and simple. The analysis and design of the grounding system are especially with different local soil characteristics and uncertain behavior.

In the current study, modeling of a fault scenario that may occur in the grounding system of a wind turbine has been carried out with the FEA software in a 2D electrostatic solver. In the second section of this paper, modeling of grounding systems of wind turbines and standards are given. In the third section, the details for the electrostatic solver are explained with the finite element method. In the next section, the earth resistance values are defined with the simulation and the potential electrostatic field analyzes of the reference earth and electrodes are performed to determine the effects related to the fault in the wind turbine grounding system by lightning impulse.

\section{MODELING OF GROUNDING SYSTEM}

To reduce greenhouse gas emissions, the development of new wind farms has led to the need to plan, design and build a certifiable grounding system that will ensure safe operation all year round. For grounding systems, it is necessary to eliminate the out-of-limit values of the step and touch voltages with respect to the reduction of earth resistance [9]. Grounding system in wind turbines consists of basis grounding, grounding grid and basis legs. In order to benefit from high wind conditions, wind turbine generators are installed in locations with few high structures. As a result, they may often be struck by lightning. This leads to failure and malfunction of the electrical, communication and control systems in and near the wind turbine generator system due to the increase in ground potential. Impact/shock tests can be performed in a real wind turbine generator system and analytical investigations based on the field tests can be performed by electromagnetic field analysis. Thus, the earth potential rise around the system and plant can be measured, analyzed and calculated by using Laplace transform to determine the voltage responses for all lightning current waveforms [10].

Grounding system analysis of a wind turbine consists of two key stages: The design and the operation stages. The design stage begins with area tests and the earth resistance measurements. The next stage is to calculate the safe step and the contact voltages based on various scenarios, such as fault type and fault times. After defining safe operation limits, real installation modeling and software simulation of phaseto-earth faults in the turbine tower base fill and in the primary substation are required. The grounding system should be designed to ensure the safety of the people nearby, livestock and equipment in the event of phase-to-earth faults or lightning impulses on the wind turbines [11]. 
A special finite element-based solution of Maxwell equations can be used for FEA of grounding systems, considering the earth electrical parameters. The importance of the earth electrical parameters can be modeled with a complex grounding system including a grounding grid of vertical and horizontal electrodes and embedded conductors. Earth electrical parameters due to sudden overvoltage caused by the lightning strikes can be affected by frequency dependence. However, the earth conductivity and relative permeability should be taken into account to accurately simulate the performance of grounding systems [12-13]. The turbine electrical system design presents a few grounding matters, which are not similar to other electrical systems. As three main grounding design pieces, they have wind turbine generators, main connectors and auxiliary interconnection nodes. These issues include system grounding, equipment grounding, and the interface with bonding and the lightning protection equipment [14-15].

The earth structure in grounding systems is determined according to the land resistance measurements. It is very important to use the appropriate method and to apply it meticulously. A grounding system is then designed for each wind turbine (WT) and control station, and improvements to the grounding system are recommended if the ground resistance and insecure touch and step voltages increase. The appropriate way to improve the grounding system for different cases is explored. In addition, the impact of concrete on the WT foundation, which aims to design a wind farm grounding system in the most efficient way, has been confirmed by measurements after wind farm construction. The design characteristics of a grounding system, methodologies for measuring ground resistance and methods of calculation step and touch voltages are described in the above-mentioned standards. IEEE Std. 80 [16], IEEE Std. 81 [17] and IEEE Std. 81.2 [18] are the most commonly used in the design of a grounding system. Various software tools have been developed to implement the requirements of IEEE Std80 in the design of grounding systems. In particular, IEC 61400-24 [19] applies to lightning protection of WT generators in wind power systems. A wind farm grounding system is designed and constructed to ensure the safety of personnel and equipment in the event of power systems failure or lightning [9].

In Ref. [20], the safety problems associated with wind turbine grounding grid systems are examined. Two different conditions are considered. The first case deals with a wind turbine exposed to a ground system fault, and the second case deals with a wind turbine which is switched off because of lightning impulses. In the first case, the fault-current distribution for various conditions are analyzed. A comparative analysis of contact and step voltages shows that the fault scenarios on the high voltage side lead to dangerous contact and step voltages. The focus is on human safety against the lightning surges. The comparative analysis of these currents for single and two turbine cases demonstrates the validity of one of the design criteria established in the international standards.

\section{ELECTROSTATIC MODELING WITH FEA}

In the modeling of physical systems, the finite element method, which has become popular in many disciplines in recent years, is frequently used. In the FEA, the problem region is analyzed by dividing it into sub-problem particles in certain sizes and geometries under certain boundary conditions. This method provides more realistic and more accurate solutions especially in nonlinear behavior modeling. The simulations can be made on electromagnetic, electrostatic, electrical and thermal issues by FEA [21]. For two-dimensional (i.e. 2D) or three-dimensional (i.e. 3D) modeling, FEA can be used as a variation solver for the mathematical solution. The problem field can be divided into finite elements as a planar element and solved as a differential equation. In this context, the FEA software uses Maxwell equations, which form the basis of electromagnetic principles for electromagnetic analysis. The differential forms of the four basic Maxwell equations are given below by Eqs. (1-4). These equations are based on Gauss, Faraday and Ampere laws [21-22]. 


$$
\begin{gathered}
\vec{\nabla} \cdot \vec{E}=\frac{\rho}{\varepsilon_{0}} \\
\vec{\nabla} \cdot \vec{B}=0 \\
\vec{\nabla} \times \vec{E}=-\frac{\partial \vec{B}}{\partial t} \\
\vec{\nabla} \times \vec{B}=\mu_{0} \vec{J}+\mu_{0} \varepsilon_{0} \frac{\partial \vec{E}}{\partial t}
\end{gathered}
$$

where, $B$ is the flux density in the units of Tesla, $E$ is the electric field in Volts per $\mathrm{cm}, J$ is the current density in Amper per $\mathrm{m}^{2}, \rho$ is the conductivity in Siemens, $\mu_{0}$ is the permeability of the vacuum as $4 \pi 10^{-}$ ${ }^{7}$ Henry per $m$, and $\varepsilon_{0}$ is 8.85 pFarad per $m$ refers to the dielectric coefficient of vacuum [21-23].

Although electromagnetic and its basic concepts are relatively simple, realistic problems can be very complicated and difficult to solve in a nonlinear media. Essentially, the analytical solutions for such problems, such as complicated geometries, nonlinear systems, and many non-static field sources, are almost impossible, and numerical methods such as the finite element method are becoming the most widely used tools in electrical engineering. The Maxwell equations in the local form consist of a strong set of equations because they are valid at any point in Fig. 1. In addition, it is easy to have algebraically short notations and adapt them to different physical situations. However, when it is necessary to apply them to a realistic case, the concepts of volume, surface and line (directly linked to the physical model itself) should be considered. In such cases, it can be adapted to a particular situation within limited conditions (local form). For instance, the Maxwell equations adapted to an electrical machine may not be suitable for analyzing a different model. On the other hand, the quantities required can be calculated by using them in integral form. In practice, in almost all cases, the integral forms of Maxwell equations are preferred to solve the relevant problem. However, the more recent differential formats are often used in FEA software solvers. In order to design and simulate electrical systems with Ansys-Maxwell software, the steps followed in electrostatic modeling are systematically followed as shown in Fig. 1 [21-23].

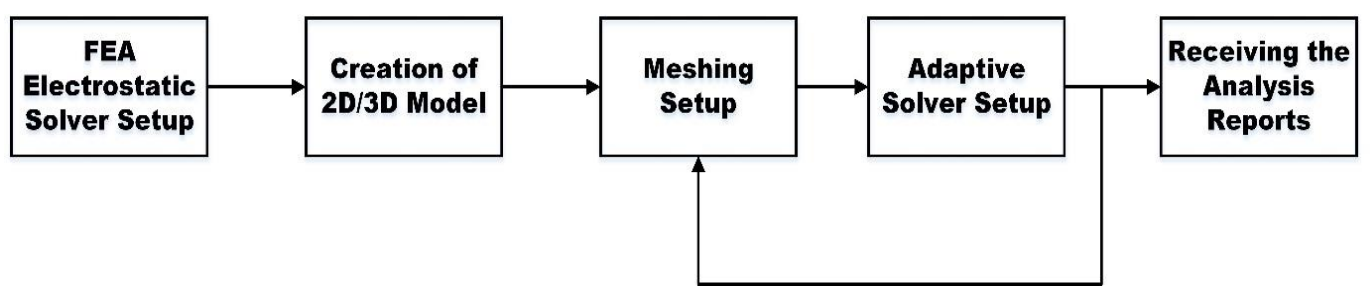

Figure 1. The steps of electrostatic modeling [21-23].

In these steps, after determining the solution type, the model geometry is drawn in 2D/3D for electromagnetic modeling and the boundaries and excitation conditions are defined. Simulation conditions for the solution setup are determined in the analysis settings stage. According to the data obtained as a result of analysis, reports such as numerical values, 2D and 3D graphs and electromagnetic field drawings are taken. In order to model the grounding system behavior with the FEA software electrostatic solver, the electromagnetic equations applicable to a grounding system containing a group of embedded vertical and horizontal conductors can be meticulously generated based on the quadratic vector wave equation, as given in Eq. 5 [12]:

$$
\nabla \times\left(\mu_{r}^{-1} \nabla \times E\right)-\omega^{2}\left(\varepsilon_{r}-j \frac{\sigma}{\omega}\right) E=0
$$


where $E$ is the electric field, $\mu_{r}$ is the relative permeability, $\varepsilon_{\mathrm{r}}$ is the relative permittivity, $\sigma$ is the electric conductivity, $\omega$ is the angular frequency, and $\nabla \times$ holds the curl of vector variables. The FEA solution to Eq. (5) is described in Eq. (6) [12]:

$$
E^{(e)}=\sum_{i=1}^{n} N_{i}^{(e)} u_{i}^{e}
$$

\section{COMPARATIVE SIMULATIONS}

Since wind turbines are generally located in rocky areas in mountainous region, there is a significant problem that soil specific resistances are very high. In order to reduce the resistances of the grounding system, it is recommended to install an expanded grounding system by electrically connecting the horizontal electrode grid structure placed around the turbine tower by IEC 61400-24 [19]. In order to calculate the step and contact voltages that will occur in case of an earth fault, simulation studies have been conducted by using CymGrd software based on finite element analysis method [2]. Similarly, in order to model faults in the grounding system for a wind turbine with Ansys-Electronics Maxwell 2D software, the foundation of the turbine of $120 \mathrm{~m}$ diameter and the grounding grid structure installed around it is shown in Fig. 2. The reference ground is defined as circular at a distance of twice rate the rotor diameter with $60 \mathrm{~m}$. The earth specific resistance value is defined as $15 \Omega \mathrm{m}$ for rocky-area [2] in the material library of Maxwell software.

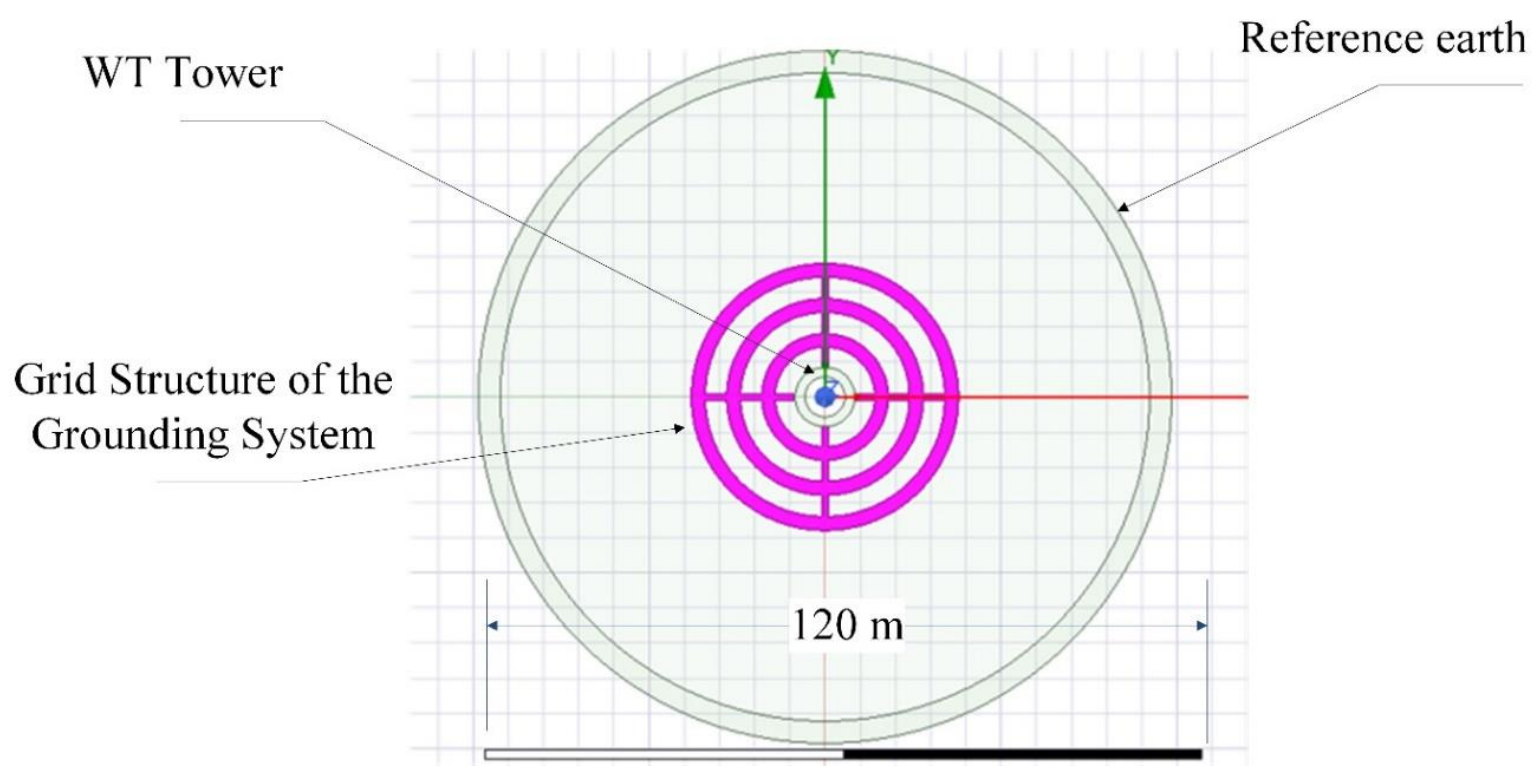

Figure 2. Wind power plant grounding system with no-fault

The meshing view of this grounding system divided into finite elements is given in Fig. 3. The maximum number of elements is $1 \mathrm{~mm}$ as the maximum element length and the maximum number of elements is meshing as 100000 . 


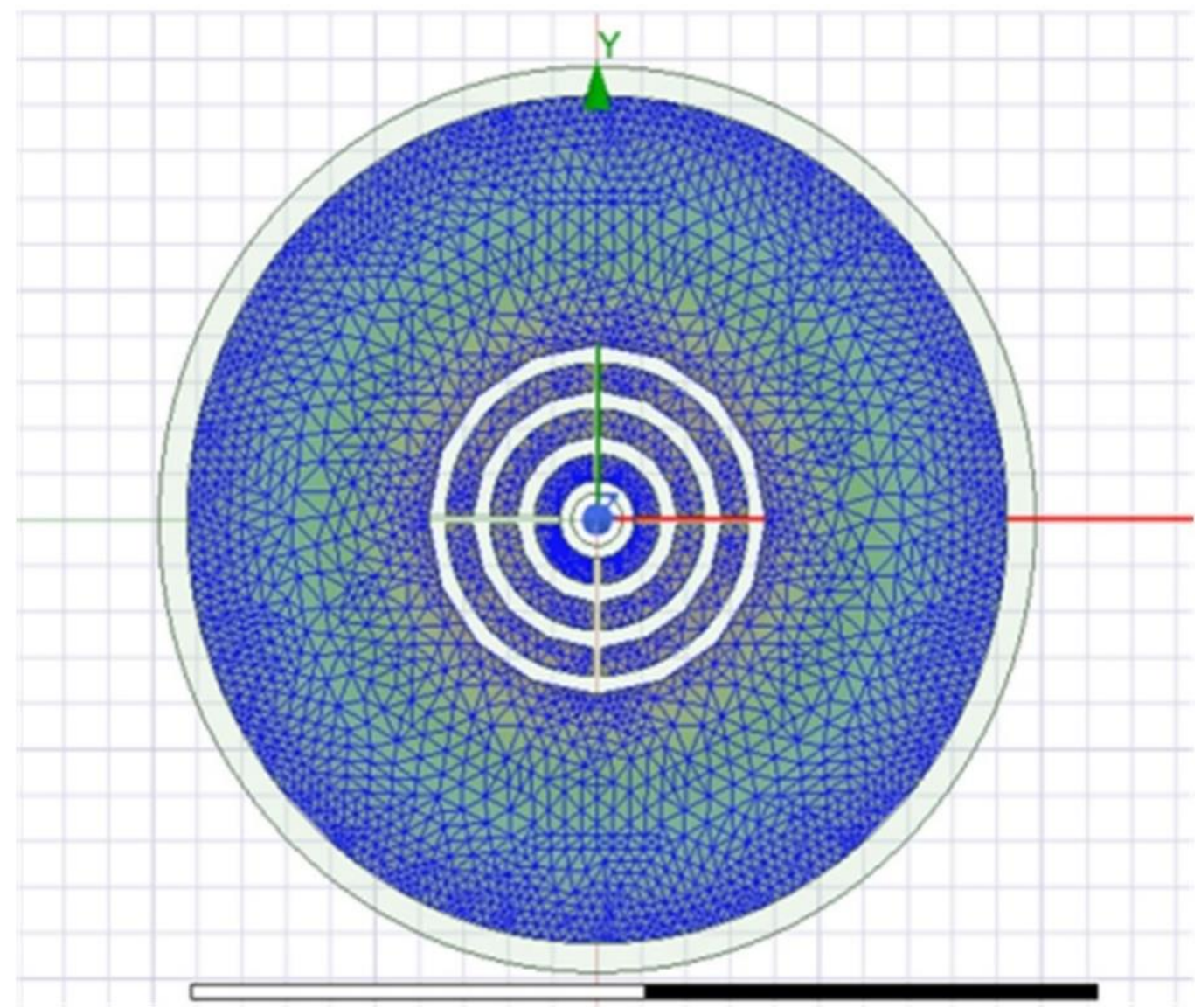

Figure 3. FEA meshing image of the grounding system.

In the absence of any fault in the grounding system, a 2D voltage distribution between the tower and the reference ground is shown in Fig. 4, where a lightning impulse of $50 \mathrm{kV}$ falls to the tower and is safely damped by the grounding system.

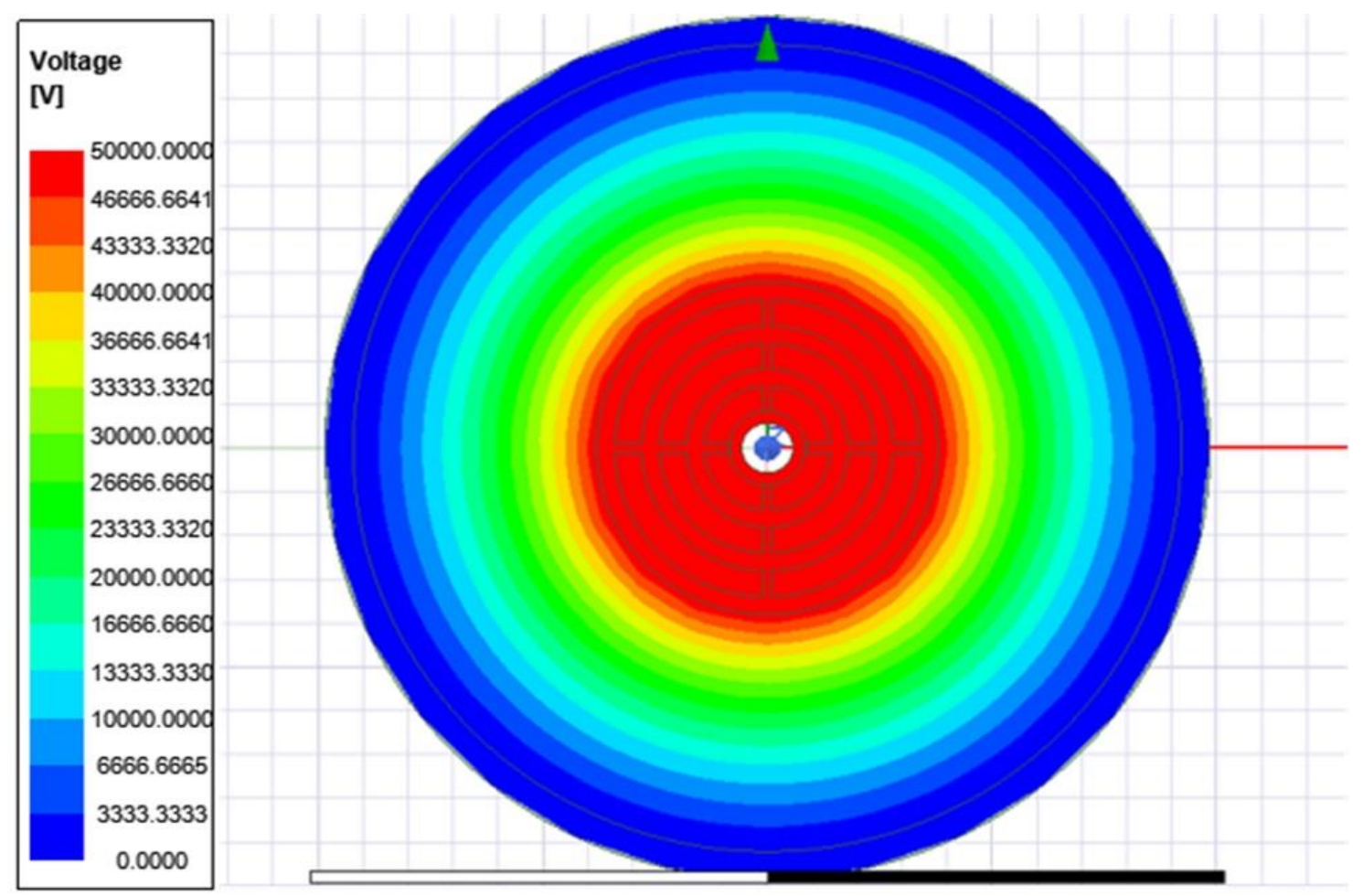

Figure 4. Voltage distribution of power plant grounding system with no-fault. 
Assuming that the electrical connection in the grounding grid structure located near the tower is broken for any reason, there is a modeling as in Fig. 5. Thus, the system behavior can be determined in case of faults in electrodes around the tower.

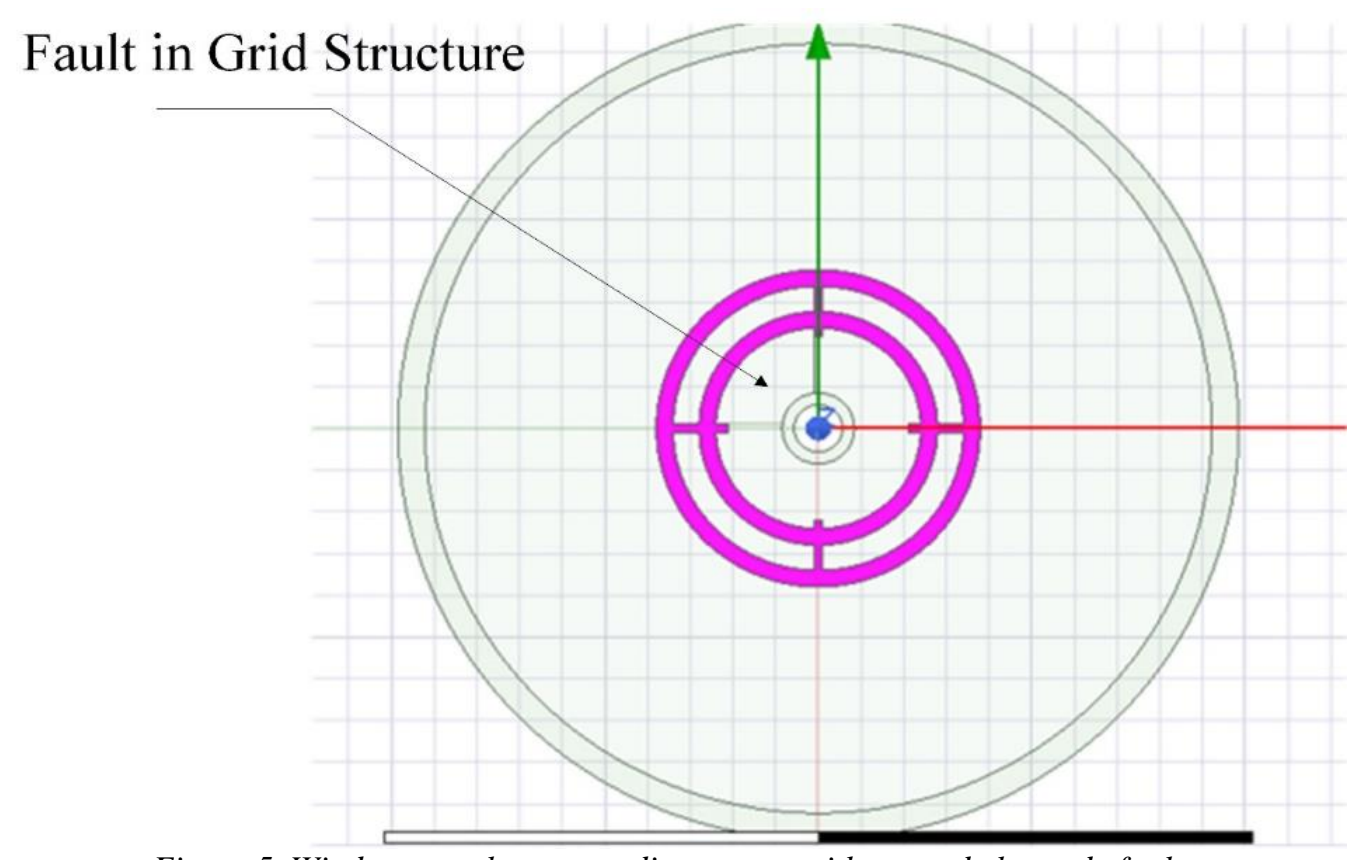

Figure 5. Wind power plant grounding system with ground electrode fault.

In the case of such a fault, the grounding system cannot absorb the $50 \mathrm{kV}$ lightning impulse towards the reference earth and therefore the wind turbine cannot be protected against the lightning impact (Fig. 6).

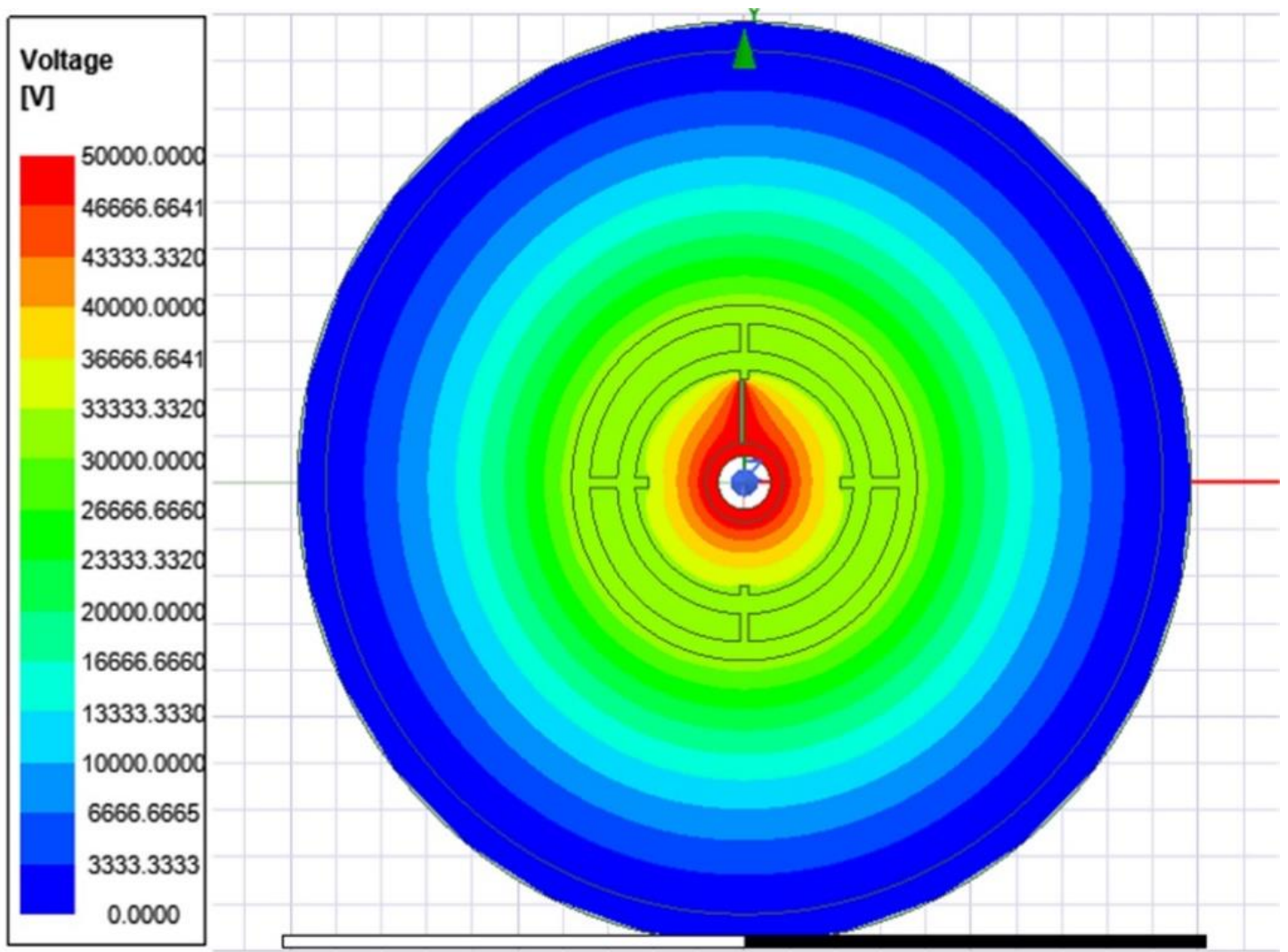

Figure 6. Voltage distribution of power plant grounding system with ground electrode fault. 


\section{CONCLUSIONS}

In this study, the modeling of a fault scenario, which may occur in the grounding system of a wind turbine, has been performed in a 2D electrostatic solver of FEA software. The FEA modeling is performed in two different conditions without any fault in the grounding system and in case of a fault in the grid structure. In the simulation studies, in order to determine the effects related to the fault in the grounding grid system by lightning impact, the soil resistance values are determined, the electric field analyzes of the reference earth and grounding grid electrodes are realized and the visual results obtained, comparatively. The voltage distribution proves that while there is no fault in the grid structure, the damping with a uniform distribution towards the reference soil occurs. However, a distortion of the voltage distribution is observed, when an electrode failure in the ground grid structure is encountered. Thus, the behavior of the faults in the grounding grid system against lightning impulse can be seen under more realistic conditions. In addition, FEA modeling may be recommended for ground system behavior and grid structure optimization in the protection of high cost systems. Furthermore, in future studies, this modeling can be improved further in a 3D media and the grounding system behavior can be determined volumetrically according to the soil layers.

\section{REFERENCES}

[1] Kargar, H.K., Sedighizadeh, M., and Mosavi, A. New grounding system of wind turbines. IEEE 43rd International Universities Power Engineering Conference, 2008, Padova, Italy.

[2] Guneri, M. Improvement of Grounding Performances in Wind Power Plants (Doctoral Dissertation). Kocaeli University. Kocaeli, Turkey, 2018.

[3] Dawalibi, F.P., and Barbeito, N. Measurements and computations of the performance of grounding systems buried in multilayer soils. IEEE Transactions on Power Delivery, 1991, 6(4), 1483-1490.

[4] Dawalibi, F.P., Ma, J., and Southey, R.D. Behavior of grounding systems in multilayer soils: A parametric analysis. IEEE Transactions on Power Delivery, 1994, 9(1), 334-342.

[5] Ma, J., and Dawalibi, F.P. analysis of grounding systems in soils with finite volumes of different resistivities. IEEE Transactions on Power Delivery, 2002, 17(2), 596-602.

[6] IEC 60909 Std. Short-circuit currents in three-phase a.c. systems - Part 0: Calculation of currents. https://webstore.iec.ch/publication/24100, 2016.

[7] Steven W. Saylors, S.W. wind farm collector system grounding. IEEE/PES Transmission and Distribution Conference and Exposition. Chicago, 2008, IL, USA.

[8] Trlep, M., Hamler, A., And Hribernik, B. The analysis of complex grounding systems by FEM. IEEE Transactions on Magnetics, 1998, 34(5), 2521-2524.

[9] Kontargyri, V.T., Gonos, I.F., and Stathopulos, I.A. Study on wind farm grounding system. IEEE Transactions on Industry Applications, 2015, 51(6), 4969-4977.

[10] Yamamoto, K., Yanagawa, S., Yamabuki, K., Sekioka, S., and Yokoyama, S. Analytical surveys of transient and frequency-dependent grounding characteristics of a wind turbine generator system on the basis of field tests. IEEE Transactions on Power Delivery, 2010, 25(4), 3035-3043.

[11] Siahpoosh, M.K., Li, L., and Dorrell, D.G. Wind farm grounding system analysis. IEEE Energy Conversion Congress and Exposition (ECCE), 2017, Cincinnati, OH, USA.

[12] Akbari, M., Sheshyekani, K., and Alemi, M.R. The effect of frequency dependence of soil electrical parameters on the lightning performance of grounding systems. IEEE Transactions on Electromagnetic Compatibility, 2013, 55(4), 739-746.

[13] Rizk, M.E.M., Mahmood, F., Lehtonen, M., Badran, E.A., and Abdel-Rahman, M.H. Induced voltages on overhead line by return strokes to grounded wind tower considering horizontally stratified ground. IEEE Transactions on Electromagnetic Compatibility, 2016, 58(6), 1728-1738.

[14] Hoerauf, R. Considerations in Wind Farm Grounding Design. 49th IEEE/IAS Industrial \& Commercial Power Systems Technical Conference (2012-PSEC-753), 2013, Stone Mountain, GA, USA, pp.1-6. 
[15] Hoerauf, R. Considerations in Wind Farm Grounding Designs. IEEE Transactions on Industry Applications, 2014, 50(2), 1348-1355.

[16] IEEE Std. 80. IEEE Guide for Safety in AC Substation Grounding, IEEE Std. 80, 2000.

[17] IEEE Std. 81. IEEE Guide for Measuring Earth Resistivity, Ground Impedance, and Earth Surface Potentials of a Ground System, ANSI/IEEE Std. 81, 2012.

[18] IEEE Std. 81.2. IEEE Guide for Measurement of Impedance and Safety Characteristics of Large, Extended or Interconnected Grounding Systems, IEEE Std. 81.2, 1991.

[19] IEC 61400-24. Wind Turbine Generator Systems - Part 24: Lightning protection, 2010.

[20] Grange, F., Journet, S., Moini, R., and Dawalibi, F.P. Safety of Wind Farm Grounding Systems under Fault and Lightning Currents. IEEE 33rd International Conference on Lightning Protection (ICLP), Estoril, Portugal, 2016.

[21] Balci, S. Modeling and Analysis of Inverter Output Transformers, (M.Sc.), Institute of Science and Technology, Gazi University, Ankara, Turkey, 2010.

[22] Bastos J.P.A., Sadowski N. Electromagnetic Modeling by Finite Element Methods, Universidade Federal de Santa Catarina Florianopolis, Copyright by Marcel Dekker. 2003, Brazil.

[23] Balci, S., Analysis of the Effect of Different Stator Slot structures on the Terminal Voltage of the Synchronous Generators with Finite Element Method, BEU Journal of Science, 2019, 8(3), 947-957. 